Shumchyk V., Milto A., Trukhan A., Slesarenok E.

\title{
Six Degrees of Separation Theory
}

Belarusian National Technical University

Minsk, Belarus

In 1929 a Hungarian author Frigyes Karinthy wrote a short story called "Chains". And in it, one character challenges the others to find another person on earth, that he cannot connect himself fewer than five intermediaries. This is the origin of six degrees of separation, which is also well known as a problem of small world. And if the theory is correct, we can be connected with Queen Elizabeth the second, Donald Trump, Johnny Depp and some man in Namibia Desert [1].

As the theory is widely accepted by more and more people, it is also considered as the motivation of online Social Network Services (SNS). Many Web 2.0 websites are based on the idea that the users would greatly increase their social capital simply because they would be able to know almost everyone on this planet within six steps of hops.

To begin with, a 'degree of separation' is a measure of social distance between people. You are one degree away from everyone you know, two degrees away from everyone they know, and so on.

What the theory really means is that we can pick two random people from different places on earth and they will be connected with six steps in average. And it was just an idea until 1960s when Harvard psychologist named Stanley Milgram attempted to test it. He called his attempt the small world experiment. What he did was he sent out 300 packages to people both in Boston and Nebraska. He wanted them to resend the package to a particular man in Boston, and they 
weren't allowed to send it directly. They were allowed to send this package to a person, who, to his mind, has more chance to know the person. Most of packages lost their way, but 64 did it to the target in average 5.2 steps. On the one hand it's the evidence. Let's take a closer look: 100 people were living in the same city, other hundred had the same profession, and finally last hundred had nothing in common. Out of this hundred only 18 were delivered. So we think that 18 packages of 300 is all the evidence there was for six degrees of separation.

There were tries to build mathematical properties on this theory. For example, famous Hungarian mathematician named Paul Erdos tried to build a theory of networks like these. But he didn't have any information on structure of real social networks, so he decided to work on networks, where connections between nodes are all completely random. So, we could call it a small world network, but it doesn't represent real life well, since we have something like "I know my friend, and he knows his friend", so all notes must be connected one another, but also we have mutual acquaintances, so small number of connections can be wired randomly. And this network is called small world network [2].

So, many people tried to work with this theory from the scientific point of view.

In 2001, Duncan Watts, a professor at Columbia University, repeated Milgram's experiment on the Internet, using an e-mail message with 48,000 senders and 19 targets. It was found that the average number of intermediaries was around six.

In 2011 the most popular social network named Facebook also decided to test the theory. Joint experiment of Facebook and Milan University found that average number of degrees is even less than six, and equally about 4.74 [3]. 
Some people criticize this experiment because they think that not all people from list of friends in social network are our acquaintances.

Another cause of criticism is that during all experiments chain of people was broken many times, at different stages. But as experimenters states, the most often cause of chain breaks was that people refuse to continue chain [4].

After all these experiments even Microsoft became interested. Company analyzed more than 30 billion emails among 180 million people all over the world. The database covered all the Microsoft Messenger instant-messaging network in June 2006, equivalent to roughly half the world's instant-messaging traffic at that time. They considered two people to be acquaintances if they had sent each other a message. The Researchers looked at minimum chain length it would take to connect 180 million different people. The result was pretty shocking: $78 \%$ of users can be connected in seven or fewer steps, but there were ones, who were separated even by 29 steps.

According to the last data this experiment was conducted 2 years ago. The point was to find a man with the help of social networks in 12 hours.

It became famous thanks to Alex Reserford from Masdar Institute of Science and technology in Abu Dhabi and social game "Tag Challenge", which was held in 2012.

The goal was to find 5 men in 5 different cities of USA and Europe. The only information about every man was city, where he was located, his photo and that he was wearing a tshirt with "Tag Challenge" logo. Alex Reserford and his team won this challenge by finding 3 of 5 men in just 12 hours [5].

The team of Alex Rutherford went their way, addressing personally those who can help in the search, based on geographical data and other information available on social 
networks. According to the team leader, it is likely that with the right approach, finding the right person can be faster.

With the help of this work we tried to show main points and interesting facts about the theory. The idea of the theory becomes widespread and is used for experiments, plots of films, games, articles and issues, modeling social structures in various industries, including IT. And it's just exciting to know how we are all connected to each other, isn't it?

References:

1. Chain Links / Karinthy T., Frigyes B. - 2009.

2. Small World Project / Dodds G., Muhamad A., Watts F. Science Magazine. - 2003. - P. 827-829.

3. An Experimental Study of the Small World Problem. Sociometry. - Volume 32. - 2016. - P. 425-443.

4. EBS Project [Electronic resource]. - Mode of access: http://erdosbaconsabbath.com. - Date of access: 12.03.2019

5. U.S. State Department Funds Fugitive Manhunt "Game" [Electronic resource]. - Mode of access http://technorati.com. - Date of access: 15.03.2019 